Article

\title{
Understanding the Determinants of $\mathrm{BnAb}$ Induction in Acute HCV Infection
}

\author{
Alexander P. Underwood ${ }^{\mathbb{D}}$, Melanie R. Walker ${ }^{\mathbb{D}}$, Nicholas A. Brasher ${ }^{\mathbb{D}}$, Auda A. Eltahla, \\ Lisa Maher, Fabio Luciani, Andrew R. Lloyd $\mathbb{D}$ and Rowena A. Bull * $\mathbb{D}$
}

School of Medical Sciences and the Kirby Institute, Faculty of Medicine, UNSW Australia, Sydney, NSW 2052, Australia; a.underwood@unsw.edu.au (A.P.U.); melanie.walker@unsw.edu.au (M.R.W.); nbrasher@kirby.unsw.edu.au (N.A.B.); a.eltahla@unsw.edu.au (A.A.E.); lmaher@kirby.unsw.edu.au (L.M.); luciani@unsw.edu.au (F.L.); a.lloyd@unsw.edu.au (A.R.L.)

* Correspondence: r.bull@unsw.edu.au; Tel.: +61-9385-2777 or +61-9385-1483

Received: 21 September 2018; Accepted: 16 November 2018; Published: 21 November 2018

check for updates

\begin{abstract}
Despite recent advances in curative therapy, hepatitis C virus (HCV) still remains a global threat. In order to achieve global elimination, a prophylactic vaccine should be considered high priority. Previous immunogens used to induce broad neutralising antibodies (BnAbs) have been met with limited success. To improve immunogen design, factors associated with the early development of BnAbs in natural infection must first be understood. In this study, 43 subjects identified with acute $\mathrm{HCV}$ were analysed longitudinally using a panel of heterogeneous HCV pseudoparticles (HCVpp), to understand the emergence of BnAbs. Compared to those infected with a single genotype, early $\mathrm{BnAb}$ development was associated with subjects co-infected with at least $2 \mathrm{HCV}$ subtypes during acute infection. In those that were mono-infected, BnAbs were seen to emerge with increasing viral persistence. If subjects acquired a secondary infection, $\mathrm{nAb}$ breadth was seen to boost upon viral re-exposure. Importantly, this data highlights the potential for multivalent and prime-boost vaccine strategies to induce BnAbs against $\mathrm{HCV}$ in humans. However, the data also indicate that the infecting genotype may influence the development of BnAbs. Therefore, the choice of antigen will need to be carefully considered in future vaccine trials.
\end{abstract}

Keywords: hepatitis $C$ virus; neutralising antibodies; vaccine; reinfection

\section{Introduction}

Despite recent advances in curative therapy, hepatitis $C$ virus $(\mathrm{HCV})$ still remains a global threat. Of the 70 million people chronically infected with HCV worldwide, by 2015 , only $13 \%$ had received curative treatment and only $20 \%$ had been diagnosed [1,2]. If left untreated, chronic HCV infection leads to progressive hepatic fibrosis, culminating in cirrhosis, liver failure, and an increased risk of hepatocellular carcinoma [3]. As transmission of $\mathrm{HCV}$ is parenteral, it is most common amongst people who inject drugs [4-6]. In most cases, acute HCV infection remains asymptomatic, allowing transmission of the virus to go undetected. Reinfection in this high-risk population is significant, and presents a significant challenge for elimination strategies $[7,8]$. For these reasons, a prophylactic vaccine still remains a priority as curative therapy alone is insufficient for global elimination [2].

To date, most prophylactic vaccines confer protection via neutralising antibodies (nAbs). In HCV, increasing evidence has shown that the emergence of nAbs, which target the envelope glycoproteins E1 and E2, play a crucial role in viral control in acute infection [9-13]. However, reinfection in high-risk populations suggests that the development of protective nAbs is difficult $[9,10,14-16]$. This may be due to the vast heterogeneity of $\mathrm{HCV}$ across populations, represented by 7 major genotypes (Gt) and over 60 subtypes [17]. In addition, the error-prone replication machinery results in rapidly mutating 
progeny, termed quasispecies, capable of evading host immune responses [18,19]. It is proposed that broad neutralising antibodies (BnAbs), capable of neutralising multiple genotypes, will need to be induced if a vaccine is to be protective $[20,21]$. So far, evidence from passive immunisation studies in animal models has suggested that BnAbs are capable of protection against a clonal viral inoculum $[14,15,22]$. However, passive immunisation in humans has only managed to delay infection of the donor liver following transplantation of $\mathrm{HCV}$-infected patients, suggesting that protection via BnAbs alone remains distant [23].

Previous attempts to induce BnAbs in humans and animal models using recombinant immunogens has been met with limited success $[23,24]$. Antibodies isolated from these subjects, while neutralising, were isolate-specific, implying that better immunogens are required. Other immunisation strategies, including multivalent and prime-boost immunisations, have been met with better success by inducing BnAbs in animal models with a breadth comparable to that in chronic infection $[25,26]$. However, the efficacy of these immunisation strategies, in humans, is yet to be determined.

Currently, little is known about the virological factors associated with successful induction of $\mathrm{BnAbs}$ in natural HCV infection. Studies in human immunodeficiency virus (HIV) have revealed the emergence of BnAbs to be associated with several parameters, including viral load, viral genotype, and duration of infection [27-29]. In HCV, BnAbs are often delayed in appearance until chronic infection has been established, and the factors associated with emergence of BnAbs remain to be discovered [11,30-32]. Understanding exactly when BnAbs emerge has been challenging, due to the difficulty in detecting the typically asymptomatic, acute HCV infections in marginalised at-risk populations.

In this study, the development of BnAbs in acute HCV infection was assessed in incident cases from a prospective cohort of HCV-negative, high-risk, injecting drug users. The development of $\mathrm{BnAbs}$ was assessed against a range of virological parameters, including viral genotype, duration of infection, mixed infection (more than one infecting HCV subtype), and reinfection. In subjects infected with only one HCV subtype (termed here mono-infected) nAbs were not seen to broaden until a late persistent infection had been established. In contrast, subjects co-infected with at least two HCV subtypes (incident mixed) developed broad $\mathrm{nAb}$ responses during early acute infection. Subjects who cleared, and then became reinfected, only demonstrated broader $\mathrm{nAb}$ responses upon re-exposure to $\mathrm{HCV}$. Collectively, the findings indicate that BnAbs are rarely elicited in a timely fashion in natural HCV infection.

\section{Materials and Methods}

\subsection{Study Cohort}

The Hepatitis C Incidence and Transmission Studies (HITS) were prospective cohorts of high-risk, HCV-seronegative/RNA-negative injecting drug users recruited from the prisons (HITS-p) and the general community (HITS-c) in New South Wales, Australia. A total of 590 subjects from 34 correctional centres were enrolled between 2005 and 2012 in HITS-p, and 268 subjects were recruited from three urban Sydney regions (southwest, inner metropolitan, and western Sydney) between 2008 and 2014 in HITS-c. Details of these cohorts have been previously reported [33-41]. All serum was tested for anti-HCV antibodies using the Abbott ARCHITECT anti-HCV chemiluminescent microparticle immunoassay (CIA) (Abbott Diagnostics, Chicago, IL, USA) and HCV RNA quantification was performed using either the VERSANT HCV RNA Qualitative Transcription Mediated Amplification (TMA) assay (Bayer Diagnostics, Emeryville, CA, USA) or the COBAS AmpliPrep/ COBAS TaqMan HCV assay (Roche, Basel, Switzerland), as previously described [37].

\subsection{Ethics}

Ethical approvals were obtained from the Human Research Ethics Committees of Justice Health (reference number GEN 31/05), the New South Wales Department of Corrective Services (reference 
number 05/0884), and the University of New South Wales (reference numbers 05094 and 08081), all located in Sydney, Australia. Written informed consent was obtained from the participants.

\subsection{Anti-Envelope Antibody ELISA}

Subject plasma was screened for anti-envelope IgG as previously described [42]. Briefly, Nunc immuno-microtitre plates (Thermo Fisher Scientific, Waltham, MA, USA) were prepared by coating each well with $500 \mathrm{ng}$ of Galanthus nivalis lectin (GNA; Sigma-Aldrich, St. Louis, MO, USA), followed by blocking the wells with 5\% skim milk (Thermo Fisher Scientific) diluted in TBS-T ( $20 \mathrm{mM}$ Tris- $\mathrm{HCl}$, pH 7.5, $150 \mathrm{mM} \mathrm{NaCl}, 0.1 \%$ Tween 20) overnight. Lysates of HEK293T cells expressing H77.20 or UKN3A.13.6 E1/E2 were captured on the GNA-coated plates. Subject plasma was heat inactivated and diluted 1:10 in 5\% skim milk TBS-T, and added to the bound antigen. Binding of IgG in plasma was detected using mouse anti-human IgG conjugated with horseradish peroxidase (Jackson ImmunoResearch, West Grove, PA, USA), followed by the addition of 3,3',5,5'-tetramethylbenzidine (TMB; Thermo Fisher). The reaction was stopped after $15 \mathrm{~min}$ with $1 \mathrm{M}$ hydrochloric acid, and plates were read at $450 \mathrm{~nm}$ on a CLARIOstar microplate reader (BMG Labtech, Mornington, Victoria, Australia). The Ab titre was expressed as a ratio of raw OD from test plasma samples and the OD of a healthy plasma sample (calculated as $\mathrm{OD}_{\text {test plasma }} / \mathrm{OD}_{\text {healthy plasma }}$ ). The ratio represents the fold difference from the healthy control.

\subsection{HCVpp Production and Neutralisation Assay}

All E1/E2 expression plasmids were previously tested in the HCVpp system (kindly gifted by Jonathan Ball) [43]. A total of $11 \mathrm{HCV}$ E1/E2 expression plasmids, representing the 6 major HCV genotypes, were used to generate heterologous HCVpp. This included H77.20 (GenBank accession AF011751), UKN1A20.8 (EU155192), UKN1B5.23 (AY734976), UKN2A1.2 (AY734977), UKN2B2.8 (AY734983), UKN3A1.28 (AY734984), UKN3A1.9 (AY734985), UKN3A13.6 (AY894683), UKN4.11.1 (AY734986), UKN5.14.4 (AY785283), and UKN6.5.340 (AY736194). The luciferase-encoding reporter plasmid (pTG126), and the murine leukaemia virus (MLV) gag/pol-encoding packaging construct (phCMV-5349) were kindly provided by Prof. Francois-Loic Cosset (University of Lyon, France).

Retroviral HCV pseudoparticles (HCVpps) were prepared as described elsewhere [43,44], based on the protocols developed by Bartosch and colleagues [45]. In brief, HCVpp was generated by co-transfecting pTG126, phCMV-5349, and a HCV E1/E2 clone onto Lenti-XR HEK293T cells (Takara, Mountain View, CA, USA), seeded the night before using a mammalian Calphos transfection kit (Takara Bio, Mountain View, CA, USA). The infectivity of the HCVpp was titrated to standardise all HCVpp to be 5-20-fold more infectious than mock pseudoparticle lacking any HCV E1/E2. Neutralisation assays were performed as previously described [9,46]. In brief, titrated HCVpp was incubated for $1 \mathrm{~h}$ with heat-inactivated plasma at a 1:50 dilution, before being added to Huh7.5 cells (Apath, New York, NY, USA). After $72 \mathrm{~h}$, the cells were lysed with a lysis buffer (Promega, Madison, WI, USA), Bright Glo reagent (Promega) was added, and luminescence was measured on a CLARIOstar microplate reader (BMG Labtech). Percentage neutralisation was calculated as (1-RLU test plasma $\left./ R L U_{\text {healthy control }}\right)$ $\times 100$. In addition to HCVpp, VSV-g pseudoparticles were tested against all subject's plasma, to demonstrate the specificity of nAbs.

\subsection{Measuring Breadth of $n$ Abs in Plasma}

To assess the breadth of $\mathrm{nAb}$ responses in plasma, a neutralisation score adapted from a HIV study was applied [28]. The scoring system accounted for both the breadth and potency of neutralising responses in plasma, whereby $>80 \%$ neutralisation received a score of $3,50 \%-80 \%$ neutralisation received a score of $2,20 \%-49 \%$ neutralisation received a score of 1 , and $<20 \%$ neutralisation received a score of 0 . Each HCVpp was scored individually, meaning that the maximum cumulative score for each plasma sample was 33 . 


\subsection{Statistical Tests}

Statistical tests were performed using GraphPad Prism software (version 7, LaJolla, CA, USA). All unpaired data was analysed using the Mann-Whitney $t$-tests, and all paired data was analysed using the Wilcoxon $t$-test. Statistical significance was defined as a $p$ value less than 0.05 . Results were expressed as a mean \pm standard deviation.

\section{Results}

\subsection{Assessing the Breadth of $n A b$ in HCV Infection}

Of the 828 subjects enrolled in the HITS-p and HITS-c cohorts, 342 (41.3\%) became positive for HCV infection, identified either through serological testing or RNA positivity. Of these 342 subjects, $126(36.8 \%)$ were identified with acute infection, and had pre-infection samples allowing calculation of the estimated days post-infection (DPI) for each follow-up sample, as described previously [47]. Of these, 9 (7.1\%) were identified as incident-mixed infection (co-infected with more than one HCV subtype at the first available viraemic time point). These subjects, as well as 34 mono-infected subjects with adequate longitudinal follow up, were selected for this study. Of these 43 subjects, 16 (37.2\%) had subsequent documented episodes of reinfection. A summary of patient demographic and virological data can be found in Table 1. 
Table 1. Patient data summary.

\begin{tabular}{|c|c|c|c|c|c|c|c|c|c|}
\hline Subject ID & Gender & Age & $\begin{array}{c}\text { Estimated Days Since } \\
\text { First Viraemic Time Point }\end{array}$ & $\begin{array}{l}\text { Infecting } \\
\text { Subtype }^{\text {a }}\end{array}$ & $\begin{array}{c}\text { Peak Viral Load } \\
\text { (IU/mL) }\end{array}$ & $\begin{array}{l}\text { Time at Peak Viral } \\
\text { Load (DPI) }\end{array}$ & $\begin{array}{l}\text { Persistent } \\
\text { Infection }\end{array}$ & $\begin{array}{l}\text { Reinfecting } \\
\text { Subtype }\end{array}$ & $\begin{array}{c}\text { Estimated Days } \\
\text { Since First Infection }\end{array}$ \\
\hline 300001 & $\mathrm{~F}$ & 26 & 155 & $3 a$ & 86,443 & 155 & - & $1 \mathrm{a}$ & 448 \\
\hline 300031 & M & 22 & 51 & Unk & 861,000 & 51 & - & - & - \\
\hline 300057 & $\mathrm{M}$ & 22 & 51 & $3 a$ & 1254 & 51 & - & - & - \\
\hline 300062 & $\mathrm{~F}$ & 25 & 95 & Unk & $<15$ & 95 & - & $1 \mathrm{~b}$ & 1079 \\
\hline 300086 & M & 22 & 51 & $2 a$ & 26,953 & 51 & - & $3 a$ & 820 \\
\hline 300089 & $\mathrm{M}$ & 23 & 179 & $1 b / 3 a$ & 70,737 & 179 & - & $3 a$ & 866 \\
\hline 300101 & $\mathrm{M}$ & 23 & 179 & $1 a / 3 a$ & $11,441,811$ & 179 & - & - & - \\
\hline 300138 & M & 21 & 191 & $3 a$ & 582 & 191 & - & $3 a$ & 386 \\
\hline 300144 & $\mathrm{~F}$ & 20 & 268 & $3 a$ & 1205 & 268 & - & 1a & 630 \\
\hline 300146 & M & 18 & 170 & Unk & $<15$ & 170 & - & - & - \\
\hline 300152 & M & 19 & 122 & Unk & $<15$ & 122 & - & $1 \mathrm{a}$ & 1157 \\
\hline 300155 & M & 27 & 217 & $3 a$ & 615 & 217 & - & Unk & 1468 \\
\hline 300168 & $\mathrm{M}$ & 18 & 4 & $1 \mathrm{~b}$ & $10,989,916$ & 32 & - & 1a & 120 \\
\hline 300212 & M & 19 & 146 & $1 \mathrm{~b}$ & 8039 & 146 & - & 1a & 358 \\
\hline 300223 & $\mathrm{~F}$ & 26 & 169 & $3 a$ & 267,750 & 169 & Y & - & - \\
\hline 300225 & M & 22 & 103 & Unk & $<15$ & 103 & - & $1 \mathrm{~b}$ & 416 \\
\hline 300230 & $\mathrm{~F}$ & 26 & 165 & $1 a / 2 a$ & 2450 & 165 & - & - & - \\
\hline 300240 & M & 18 & 45 & $3 a$ & 54,887 & 58 & Y & - & - \\
\hline 300256 & $\mathrm{M}$ & 24 & 44 & $1 a / 3 a$ & $34,149,824$ & 44 & Y & - & - \\
\hline 300259 & M & 20 & 41 & $3 a / 2 a$ & 567,122 & 41 & Y & - & - \\
\hline 300270 & $\mathrm{M}$ & 25 & 173 & $6 a$ & 10,671 & 173 & Y & - & - \\
\hline 300272 & F & 29 & 61 & $3 a$ & 10,122 & 61 & - & $1 \mathrm{a}$ & 2270 \\
\hline 300277 & M & 18 & 39 & $3 a / 3 b$ & $5,482,503$ & 63 & - & - & - \\
\hline 300280 & F & 19 & 176 & $1 \mathrm{a}$ & $22,384,668$ & 176 & - & - & - \\
\hline 300303 & $\mathrm{~F}$ & 40 & 48 & $1 a / 3 a$ & $5,052,079$ & 48 & - & - & - \\
\hline 300304 & M & 46 & 43 & $1 a / 3 a$ & $1,436,063$ & 114 & Y & - & - \\
\hline 300315 & M & 21 & 51 & $2 b$ & 872,728 & 51 & Y & - & - \\
\hline 300327 & M & 28 & 101 & $2 \mathrm{~b}$ & 6748 & 146 & Y & - & - \\
\hline 300329 & $\mathrm{M}$ & 19 & 104 & $3 a$ & 9504 & 177 & Y & - & - \\
\hline 300354 & M & 18 & 127 & $1 \mathrm{a}$ & 23,573 & 127 & - & $1 \mathrm{a}$ & 336 \\
\hline 300360 & $\mathrm{M}$ & 23 & 30 & $3 a$ & $5,648,631$ & 30 & - & - & - \\
\hline 300374 & M & 23 & 145 & $1 a / 3 a$ & 44,836 & 145 & - & - & - \\
\hline 300472 & M & 22 & 84 & $1 \mathrm{a}$ & $1,263,375$ & 84 & Y & - & - \\
\hline 300494 & $\mathrm{~F}$ & 23 & 174 & $2 \mathrm{~b}$ & 73,841 & 174 & Y & - & - \\
\hline 300499 & $\mathrm{M}$ & 23 & 169 & 1a & 591,430 & 169 & - & - & - \\
\hline 400087 & M & 23 & 31 & $1 \mathrm{~b}$ & $13,118,082$ & 42 & - & $3 a$ & 49 \\
\hline FRKT0686FX & M & 22 & 41 & 1a & $2,404,901$ & 41 & - & - & - \\
\hline JEBJ0991MX & $\mathrm{M}$ & 18 & 74 & $1 \mathrm{a}$ & 1037 & 74 & - & - & - \\
\hline KAMA0984MX & M & 24 & 88 & Unk & $<15$ & 88 & - & $3 a$ & 591 \\
\hline KIMB0979FX & $\mathrm{F}$ & 29 & 98 & Unk & $<15$ & 98 & - & - & - \\
\hline MCRL0786FX & $\mathrm{F}$ & 22 & 81 & $1 \mathrm{a}$ & 1846 & 81 & - & - & - \\
\hline MIJC1076FX & $\mathrm{F}$ & 32 & 126 & $1 \mathrm{a}$ & 15,997 & 175 & - & - & - \\
\hline NASS0384MX & $\mathrm{M}$ & 25 & 84 & $3 a$ & 5321 & 94 & - & $3 a$ & 84 \\
\hline
\end{tabular}


All subjects were initially screened for anti-envelope antibodies using an HCV-specific IgG detection ELISA. To confirm that neutralisation in plasma was due to HCV-specific IgG responses, the anti-envelope antibody titre $\left(\mathrm{OD}_{450}\right.$ signal/noise) was compared to the neutralisation of a HCVpp carrying the reference envelope sequence (H77.20 or UKN3A13.6). As shown in Figure 1a,b, a significant correlation was found $(r=0.953, p<0.0001$; and $r=0.821, p<0.0001)$, indicating that neutralisation of HCVpp was likely to be due to the presence of anti-envelope IgG.

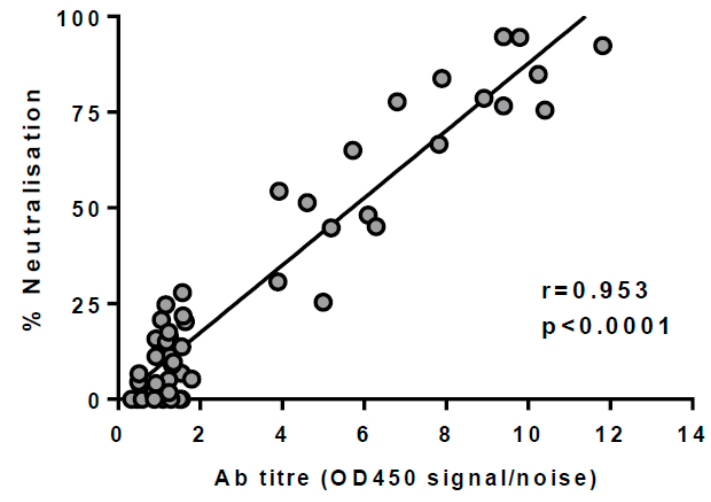

(a)

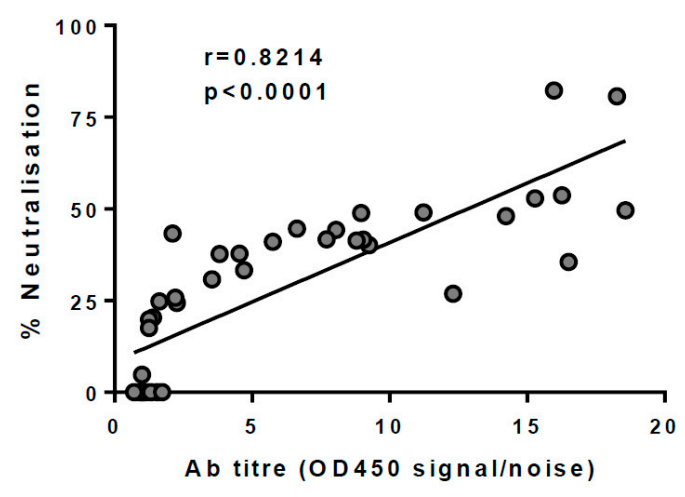

(b)

Figure 1. Linear regression analysis of anti-E1/E2 IgG titres (optical density $450 \mathrm{signal} / \mathrm{noise}$ ) and percentage neutralisation (\%) of HCVpp carrying the same envelope sequence. A significant correlation was found in (a) matched Gt1 envelope sequences (H77.20, $r=0.953, p<0.0001)$ and (b) matched Gt3 envelope sequences (UKN3A.13.6, $r=0.8214, p<0.0001$ ) demonstrating that neutralisation of HCVpp was likely be associated with anti-envelope $\operatorname{IgG}$ in the plasma.

To assess the breadth of neutralisation in plasma, a panel of $11 \mathrm{HCVpp}$, representing envelope proteins from HCV genotypes 1-6, was used. As shown in Figure 2, neutralisation breadth and potency against these HCVpp was summarised using a neutralisation score adapted from a comparable approach taken in HIV [28]. Given that it is unclear what percentage of neutralisation has biological relevance in vivo, this approach avoided the application of a single arbitrary cut off. However, to assess the validity of a lower cut off ( $20 \%$ neutralisation), 17 subjects that had plasma available pre-infection $(n=17)$ were compared to a healthy control. As shown in Figure 3, 14 of the 17 subjects' neutralising activity against the $11 \mathrm{HCVpp}$ were all under the $20 \%$ cut off. The three remaining subjects each reacted to only 1 of the $11 \mathrm{HCVpp}$ tested: subject 300146 (UKN3A1.9, 27.9\% neutralisation), 300225 (UKN1A20.8, 21.0\% neutralisation), KIMB0979FX (UKN3A13.6, 21.7\% neutralization), and NASS0384MX (UKN3A1.9, 20.5\% neutralisation). Given that 97.9\% (4 of 187 HCVpp) of the neutralising activity was below this threshold, this validated the use of a lower neutralisation cut off. 


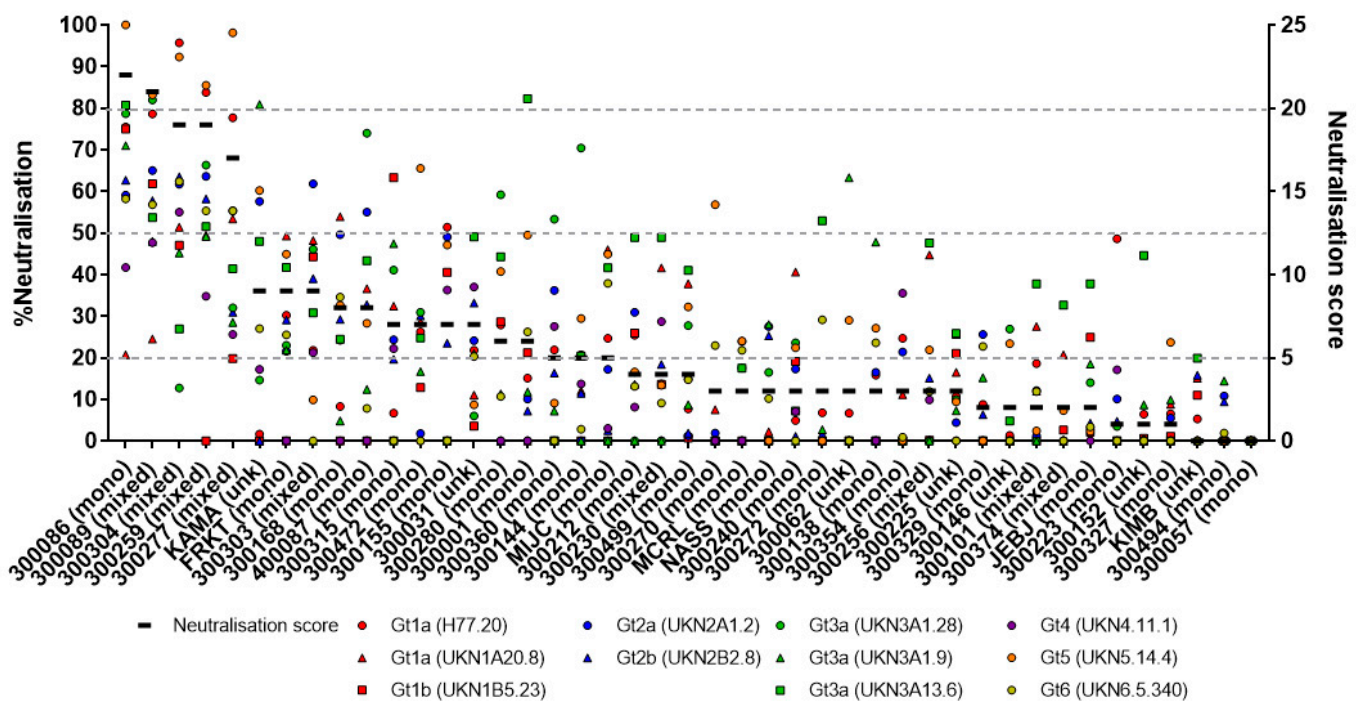

Figure 2. Individual analysis of the neutralisation activity against $11 \mathrm{HCVpp}$ for the 43 subjects included in this study. Subject ID is indicated on the $x$ axis, and infection history (mono-, mixed, or unknown [unk] infection, is indicated in parentheses). The neutralisation score (black line for each subject and right-hand y axis) applied for each subject (listed on the $\mathrm{x}$ axis) is observed to summarise both the breadth (multiple HCVpp neutralised) and neutralisation potency (left-hand y axis) of each HCVpp, representing an accurate summary of overall neutralisation potential. Each grey line represents the cut off for each part of the scoring system.

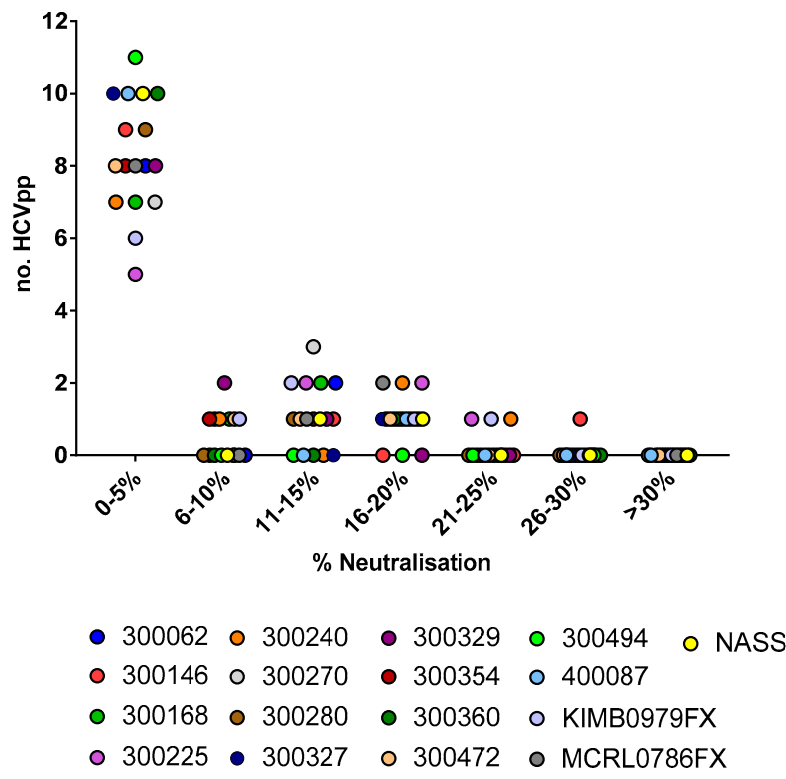

Figure 3. Neutralising activity of available plasma samples (diluted 1:50) collected pre-HCV infection $(n=17)$ compared to a healthy control. All 17 subjects were tested against a panel of 11 HCVpp, representing GT1 to 6 . While all subjects demonstrated some neutralising activity, this was below the $20 \%$ cut off (grey line) with the exception of single HCVpp for subjects 300146 (UKN3A1.9, 27.9\% neutralisation), 300225 (UKN1A20.8, 21.0\% neutralisation), KIMB0979FX (UKN3A13.6, 21.7\% neutralisation), and NASS0384MX (UKN3A1.9, 20.5\% neutralisation). Given that $97.9 \%$ of neutralising activity was below this threshold, this validated the use of a lower neutralisation cut off.

\subsection{Early Induction of Broad $n A b$ s Was Associated with Incident Mixed Infections}

Upon ranking the neutralisation scores (Figure 2), it was noted that many of the highest-ranked subjects had an incident mixed infection. To evaluate whether harbouring two genotypes, compared 
to a single genotype, influenced the development of $\mathrm{nAb}$ breadth and potency, neutralisation scores between incident mixed $(n=9)$ and mono-infected $(n=31)$ subjects were compared (Figure $4 \mathrm{~A})$. Subjects 300138, 300144, and 300155 were excluded from this analysis due to their first viraemic time point being estimated to have been detected during the chronic stages of infection (>180 DPI). Incident mixed subjects were found to have significantly higher neutralisation scores $(p=0.0126)$ suggesting that the presence of multiple infecting genotypes influences early BnAb development. However, neutralisation scores between incident mixed subjects were also noted to vary considerably (Figure 4A). To address whether this was related to particular combinations of genotypes, incident mixed subjects were separated based on the infecting genotypes, and the neutralisation scores were compared (Figure 4B). Despite the limited sample size, subjects infected with a non-Gt1a strain had a significantly higher neutralisation score compared to those with Gt1a ( $p=0.0495)$, suggesting that the infecting genotype may influence BnAb development. Further, as shown in Figure $4 \mathrm{C}$, those mono-infected with Gt1 had a moderate, but significantly broader $\mathrm{nAb}$ response, than those infected with Gt3 ( $p=0.0458$ ). It should be noted that a single outlier subject infected with Gt 2 had the best overall neutralisation score in the mono-infection group (subject ID: 300086), however, this was not found in others infected with the same genotype (Figure 4C). Collectively, this data indicates that the $\mathrm{BnAb}$ responses during acute $\mathrm{HCV}$ infection may be associated with the presence of multiple genotypes, particularly multiple genotypes with the exclusion of Gt1a.

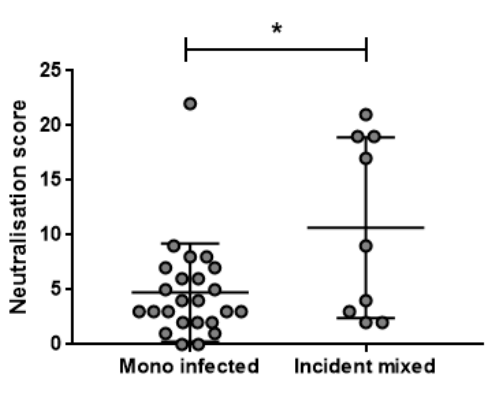

(A)

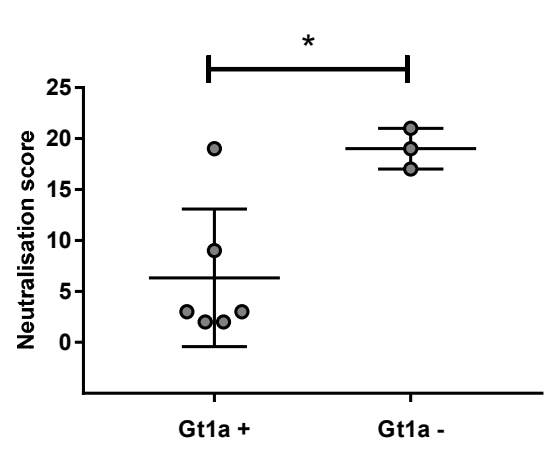

(B)

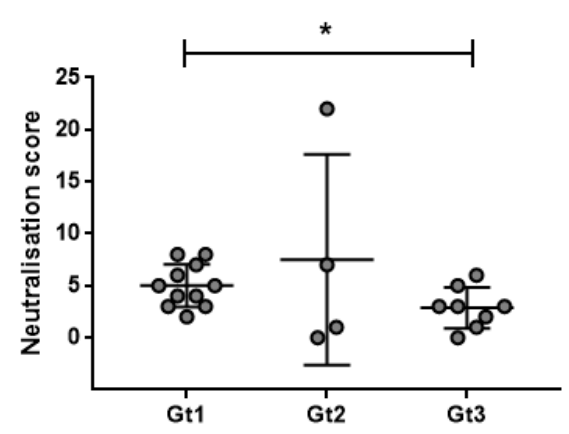

(C)

Figure 4. Comparison of neutralisation scores in different genotype infections. (A) Incident mixed subjects had a significantly greater neutralisation score compared to those who were mono-infected ( $p=0.0123$, Mann-Whitney $t$-test). (B) Incident mixed subjects that did not have Gt1a detected during infection had a significantly higher neutralisation score than those that did ( $p=0.0495$, Mann-Whitney $t$-test). (C) In mono-infections, those infected with Gt1 had a significantly higher neutralisation score compared to Gt3 mono-infections ( $p=0.0458$, Mann-Whitney $t$-test). Subjects 300138, 300144, and 300155 were excluded from this analysis due to their first viraemic time points being estimated to have been detected after chronic viraemia had been established. 


\subsection{Breadth of $n A b s$ is Boosted with Re-Exposure to HCV}

In order to assess whether re-exposure to HCV influenced neutralisation breadth, the scores between primary and acute secondary infections were compared in 16 subjects with documented reinfection (Table 1). Collectively, secondary infections had significantly higher neutralisation scores $(p=0.0458)$ than primary infections, suggesting the breadth of nAbs may be boosted upon HCV re-exposure (Figure 5A). In 4 subjects, however, neutralisation scores were not found to be boosted upon re-exposure. Of these 4 subjects, 3 were re-exposed to a heterologous genotype, suggesting that homologous re-exposure may be more beneficial for inducing BnAbs. To further investigate this possibility, neutralisation scores were compared between primary and secondary infections, with homologous and heterologous genotypes upon re-exposure (Figure 5B). Four subjects could not be included in this analysis, due to the viral load being too low to identify the infecting genotype (subject ID: 300062, 300152, 300225, and KAMA0984MX). Generally, those re-exposed to a homologous genotype demonstrated a better boost in neutralisation score, however, this was not significant $(p=0.247$, Figure 5B).

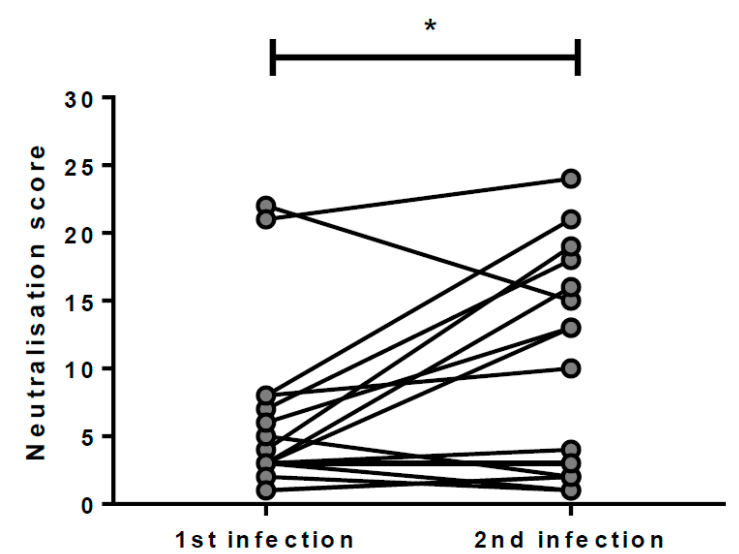

(A)

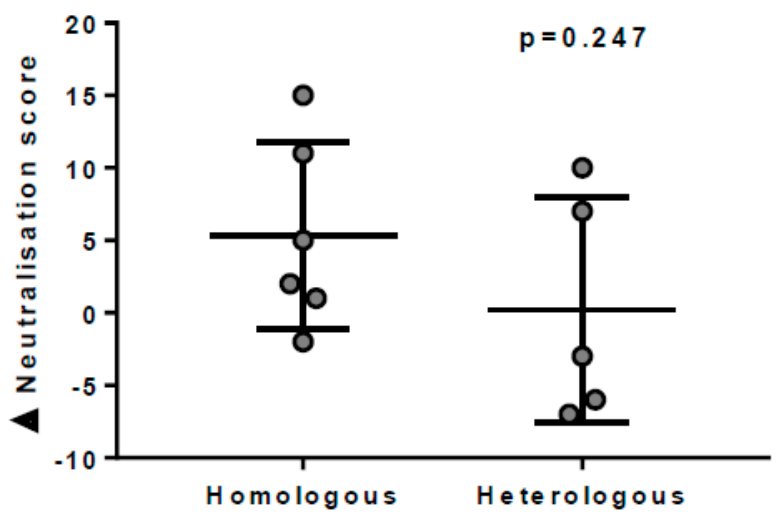

(B)

Figure 5. Comparison of neutralisation scores between primary and secondary infections. (A) Neutralisation scores in acute secondary infections were found to be significantly higher than acute primary infections ( $p=0.0494$, Wilcoxon $t$-test). (B) The difference in neutralisation scores between primary and secondary infections in homologous and heterologous reinfections was not found to be significant $(p=0.247$, Mann-Whitney $t$-test). Subject 300089 was excluded from this analysis, due to incident mixed primary infection.

\subsection{Prolonged Antigen Exposure Is Associated with Broader nAb Development in Mono-Infection}

In order to assess the effect of prolonged antigen exposure on $\mathrm{nAb}$ responses, neutralisation scores were analysed longitudinally in those that developed a persistent mono-infection $(n=6$, subject ID: 300240, 300270, 300327, 300329, 300472, and 300494). A linear relationship between duration of infection and neutralisation scores was observed, indicating that nAbs broadened with increased antigen exposure (Figure 6A). However, the time taken for nAbs to broaden was slow, taking years to reach levels similar to those observed for acute incident mixed infections. As two of the incident mixed infection subjects were found to develop a persistent infection (subject ID: 300259 and 300304), these were examined longitudinally, to assess the combined influence of incident mixed and persistent infection (Figure 6B). In contrast to mono-infections, neutralisation scores were not seen to increase with persistent viraemia in incident mixed infections (Figure 6B). 


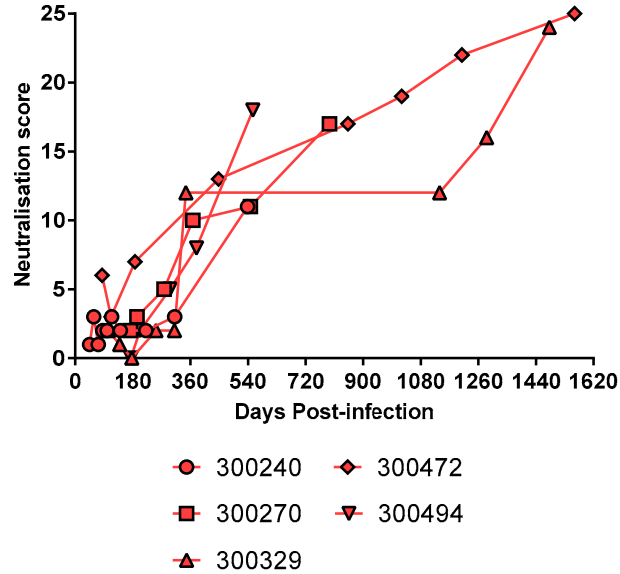

(A)

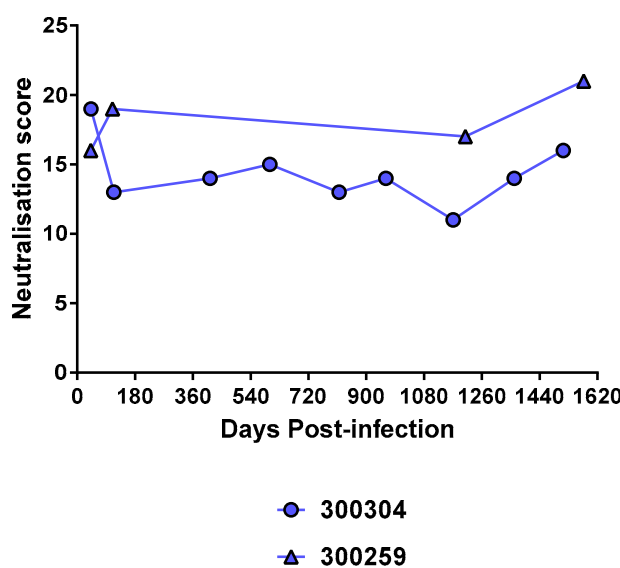

(B)

Figure 6. Neutralisation scores analysed longitudinally in persistent (A) mono-infections and (B) incident mixed infections. Neutralisation scores in mono-infections increased with the duration of the infection. These scores did not reach a comparable level to incident mixed infections until 700 days post-infection. In incident mixed infections, neutralisation scores developed earlier than mono-infections but did not increase with persistent viraemia.

\subsection{Breadth Is Not Associated with Viral Load}

To determine if viral load influenced the emergence of BnAbs, the peak viral load detected during acute infection was compared to the peak neutralisation score. While there was a moderate positive relationship between these variables $(r=0.299)$, this was not found to be significant $(p=0.0641$, Figure 7).

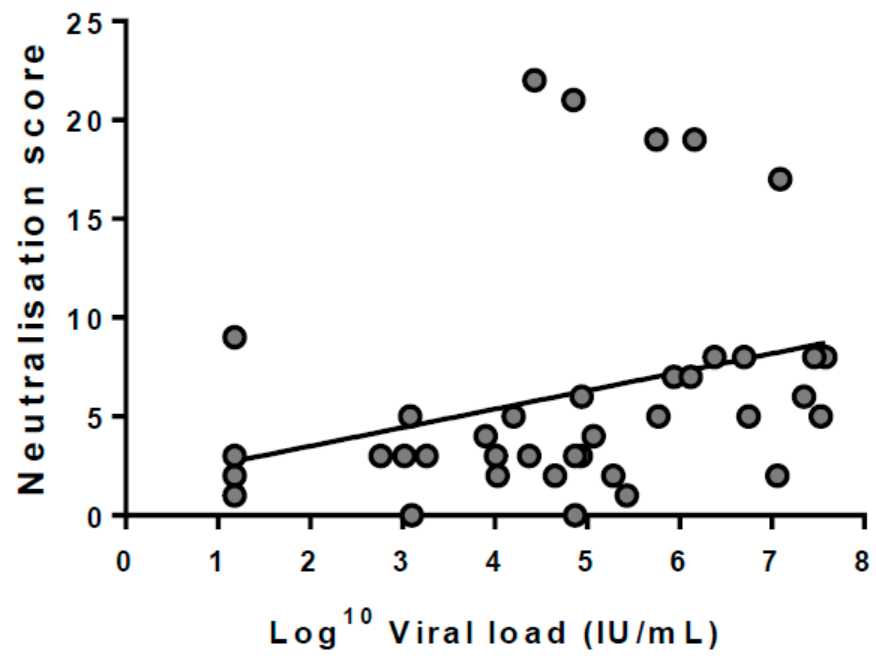

Figure 7. Linear regression analysis between the neutralisation score and peak viral load detected during acute viraemia $(\mathrm{IU} / \mathrm{mL})$. Although a modest correlation was found $(r=0.299)$, this was not significant $(p=0.0641)$.

\section{Discussion}

For highly diverse viruses, such as $\mathrm{HCV}$, a vaccine that can induce BnAbs is considered ideal (reviewed in $[20,21])$. However, in the context of infection, BnAbs typically do not develop until chronic infection has been established [11,30-32], suggesting an intrinsic or virus-induced defect, and, thus, presenting a challenge for vaccine design. This uncertainty highlights the need to better understand 
the parameters involved in successful induction of BnAbs to inform vaccine development. The present study firstly suggests that breadth in the immunogen (or, in this case, divergent infecting genotypes) represents one such parameter for induction of BnAb responses. Secondly, the data reported here indicate that $\mathrm{BnAb}$ responses develop slowly, either reflecting the need for considerable somatic hypermutation, or $\mathrm{T}$ cell help, or both. Thirdly, the findings in reinfection generally suggested that memory responses had been established, as boosting was evident upon re-exposure.

By examining antibody responses in a group of acutely infected individuals, the findings presented here indicate that $\mathrm{BnAb}$ responses may be best elicited by the presence of multiple immunogens during early HCV infection. Successful vaccines against many pathogens, such as poliovirus and human papilloma virus (HPV), offer their success to polyvalent immunogens, designed to increase the breadth of immune responses by the incorporation of immunogens from multiple strains. In a recent report, mice and macaque animal models immunised against HCV developed broader nAbs when a multivalent vaccine approach was administered [25]. By incorporating more than one immunogen, $\mathrm{B}$ cell clones with higher affinity to the variants, either individually or combined, may have a competitive advantage and, thus, broader $\mathrm{nAb}$ responses may be elicited. Noting the counter-concern of antigenic competition abrogating $\mathrm{BnAb}$ generation, it is reassuring to note that the results presented here, from subjects with incident mixed HCV infection, highlight the potential for a multivalent vaccine approach to induce BnAbs in humans.

The major goal of vaccination is to generate long-term protection against infection. For pathogens like hepatitis B virus (HBV), protection is conferred by repeated dose regimens that are designed to generate long-lasting immunity. In previous reports, episodes of reinfection have been reported to boost antibody titres against HCV, however, the impact of these exposures on breadth were not investigated $[9,10]$. Building upon these studies, the limited dataset presented in this study indicates that neutralising responses generally broadened when re-exposed to HCV. This outcome has also been observed in animal models undergoing HCV prime-boost vaccine trials [26]. While it is suggested that boosting with a heterologous virus can induce broader immune responses than homologous re-exposure (reviewed in [48]), in the reinfection cases reported here, there were no significant differences between naturally occurring homologues of these immunogens in the form of divergent genotype (heterologous) versus same-genotype (homologous) natural HCV infections.

In this regard, it is important to consider that the E1/E2 proteins generally differ between genotypes by approximately 30\%, and between subtypes by approximately 15\% (reviewed in [21]). Thus, the within-genotype re-exposure still offers a moderately non-conserved protein. This lack of conservation is generally reflected in hypervariable regions and neutralising antibody domains (reviewed in [20]), which may account for the boost in breadth with homologous re-exposure. It is also worth noting that the prime-boost immunisation strategy relies on B cell responses from the previous exposure being recalled to undergo further affinity maturation in the germinal centre, and usually increased breadth [49]. However, this strategy relies on good memory B cell responses being induced with the primary exposure, and sufficient cross-reactivity with the second immunogen to ensure cross-recognition and, thus, recall of these memory B cell responses. For the minority of subjects that failed to boost upon re-exposure to $\mathrm{HCV}$, this may be reflected by poorly induced memory $B$ cells during the first encounter with the virus (neutralisation score $<5$ ). To date, there has been limited investigation of memory recall in HCV. Collectively, the natural history infection data in this study suggests that, in some instances, a prime-boost vaccine regimen can effectively induce BnAbs against $\mathrm{HCV}$.

For other highly diverse RNA viruses, like HIV and influenza, the strain of antigen presented has been shown to significantly impact the breadth of the host immune response [28,50]. The choice of immunogen must be carefully considered if a protective vaccine against HCV is to be developed. In most $\mathrm{HCV}$ vaccine trials to date, the formulations used to generate $\mathrm{nAbs}$ have typically included Gt1-based envelopes [24,26,51]. However, the present findings indicate that, while Gt1 mono-infections were found to induce broader $\mathrm{nAb}$ responses, the presence of $\mathrm{Gt} 1 \mathrm{a}$ hindered breadth development 
in incident mixed infections. The conclusions drawn here are, however, limited by the sample size and the fact that the Gt1 HCVpp may be more closely related to autologous virus compared to the Gt3 HCVpp. Compared to Gt3, Gt1 E1/E2 has a greater intra-host diversity within the quasispecies [52], which may positively influence $\mathrm{BnAb}$ development in mono-infections. However, this diversity could dominate antigen presentation in incident mixed individuals masking presentation of antigen from other circulating genotypes. It is, therefore, important that future studies investigate different combinations of HCV antigens, in order to optimise early BnAb induction. While the emergence of nAbs has been linked to improved viral control [12], how or when nAbs begin to broaden remains relatively unknown. Previous studies have linked the early appearance of BnAbs to spontaneous resolution of the virus $[11,53]$. Previous longitudinal analyses on persistently infected individuals has shown that nAbs begin to become broad around 100 weeks post-infection (700 DPI) [30]. However, the panel of HCVpp used in these studies was limited to only a single genotype (Gt1), and does not accurately reflect cross-genotypic breadth. Building on this, the current data indicate that $\mathrm{nAbs}$ continue to broaden slowly with an increasing duration of viral persistence, similar to that seen in HIV infection [54]. Interestingly, the breadth of the $\mathrm{nAb}$ response in mono-infections was not comparable to that of broad incident mixed subjects until 700 days of infection had passed. By contrast, BnAbs were induced during early incident mixed infections, but were not influenced by increasing viral persistence. This finding suggests either that the breadth of neutralisation potential in certain individuals is limited or, alternatively, that the delay is a virus-induced phenomenon. Importantly, these data highlight the best means to induce BnAbs early during antigen encounter.

Several cross-sectional studies in HIV have demonstrated a link between the amount of antigen (viral load) and the breadth of $\mathrm{nAb}$ responses [55,56]. Interestingly, in chronic HCV, broader antibody profiles have been associated with lower viral loads [57]. However, this latter observation may be due to antibody responses suppressing the viral load in these individuals prior to the subsequent viral escape at the $\mathrm{nAb}$ epitope(s) and rise in viral load. Such viral load analyses are often heavily biased by the time at which samples are collected (reflecting the duration of viraemia). Despite attempting to reduce this bias by using the peak viral load detected during acute viraemia, only a modest relationship between viral load and $\mathrm{nAb}$ breadth could be determined.

In conclusion, this study shows that the development of broad $\mathrm{nAb}$ responses against $\mathrm{HCV}$ is difficult, typically taking years to manifest in typical mono-infections. By contrast, the rapid induction of BnAbs in incident mixed infection episodes helps provide the proof-of-principle for multivalent and prime-boost immunisation strategies. The success of these immunisations may rely on the use of carefully selected immunogens with the greatest propensity for induction of BnAbs across individuals.

Author Contributions: Conceptualization, R.A.B. and A.R.L.; Methodology, R.A.B., M.R.W. and A.U.; Formal Analysis, A.U., A.A.E.; Investigation, A.U. and N.A.B.; Resources, A.R.L. and L.M.; Writing-Original Draft Preparation, A.U.; Writing—Review \& Editing, R.A.B., A.A.E. and A.U.; Funding Acquisition, R.A.B., F.L. and A.R.L.

Funding: This work was supported by the Australian Government Department of Health National Health and Medical Research Council (NHMCR, https: / / www.nhmrc.gov.au/) grants including NSW Health, Justice Health, and Corrective Services NSW as partners (222887 and 1016351); and by a National Health and Medical Research Council of Australia Practitioner Fellowship (1043067 to A.R.L.). R.A.B. is supported by a NHMRC Career Development Fellowship (APP1084706).

Acknowledgments: The HITS-p investigators include Kate Dolan, Paul Haber, William Rawlinson, Carla Treloar, Greg Dore, Lisa Maher, and Andrew Lloyd and Fabio Luciani. We would like to thank Francois-Loic Cosset for the MLV plasmids, Shoshana Levy for the CD81 plasmids, Jonathan Ball and Alexander Tarr for HCV Envelope encoding plasmids, Steven Foung and Richard Urbanowicz for assistance with the HCVpp assay.

Conflicts of Interest: The authors declare no conflict of interest. 


\section{References}

1. Blach, S.; Zeuzem, S.; Manns, M.; Altraif, I.; Duberg, A.S.; Muljono, D.H.; Waked, I.; Alavian, S.M.; Lee, M.H.; Negro, F.; et al. Global prevalence and genotype distribution of hepatitis C virus infection in 2015: A modelling study. Lancet Gastroenterol. Hepatol. 2017, 2, 161-176. [CrossRef]

2. World Health Organization. Global Hepatitis Report 2017; World Health Organization: Geneva, Switzerland, 2017.

3. Bowen, D.G.; Walker, C.M. The origin of quasispecies: Cause or consequence of chronic hepatitis C viral infection? J. Hepatol. 2005, 42, 408-417. [CrossRef] [PubMed]

4. Grebely, J.; Dore, G.J.; Morin, S.; Rockstroh, J.K.; Klein, M.B. Elimination of HCV as a public health concern among people who inject drugs by 2030-What will it take to get there? J. Int. AIDS Soc. 2017, 20, 22146. [CrossRef] [PubMed]

5. Page, K.; Morris, M.D.; Hahn, J.A.; Maher, L.; Prins, M. Injection drug use and hepatitis C virus infection in young adult injectors: Using evidence to inform comprehensive prevention. Clin. Infect. Dis. 2013, 57 Suppl. S2, S32-S38. [CrossRef]

6. Wiessing, L.; Ferri, M.; Grady, B.; Kantzanou, M.; Sperle, I.; Cullen, K.J.; EMCDDA DRID Group; Hatzakis, A.; Prins, M.; Vickerman, P.; et al. Hepatitis C virus infection epidemiology among people who inject drugs in europe: A systematic review of data for scaling up treatment and prevention. PLoS ONE 2014, 9, e103345. [CrossRef] [PubMed]

7. Martinello, M.; Grebely, J.; Petoumenos, K.; Gane, E.; Hellard, M.; Shaw, D.; Sasadeusz, J.; Applegate, T.L.; Dore, G.J.; Matthews, G.V. HCV reinfection incidence among individuals treated for recent infection. J. Viral Hepat. 2017, 24, 359-370. [CrossRef] [PubMed]

8. Martinello, M.; Hajarizadeh, B.; Grebely, J.; Dore, G.J.; Matthews, G.V. HCV cure and reinfection among people with HIV/HCV coinfection and people who inject drugs. Curr. HIV/AIDS Rep. 2017, 14, 110-121. [CrossRef] [PubMed]

9. Dowd, K.A.; Netski, D.M.; Wang, X.H.; Cox, A.L.; Ray, S.C. Selection pressure from neutralizing antibodies drives sequence evolution during acute infection with hepatitis C virus. Gastroenterology 2009, 136, 2377-2386. [CrossRef] [PubMed]

10. Osburn, W.O.; Fisher, B.E.; Dowd, K.A.; Urban, G.; Liu, L.; Ray, S.C.; Thomas, D.L.; Cox, A.L. Spontaneous control of primary hepatitis $C$ virus infection and immunity against persistent reinfection. Gastroenterology 2010, 138, 315-324. [CrossRef] [PubMed]

11. Osburn, W.O.; Snider, A.E.; Wells, B.L.; Latanich, R.; Bailey, J.R.; Thomas, D.L.; Cox, A.L.; Ray, S.C. Clearance of hepatitis $C$ infection is associated with the early appearance of broad neutralizing antibody responses. Hepatology 2014, 59, 2140-2151. [CrossRef] [PubMed]

12. Pestka, J.M.; Zeisel, M.B.; Blaser, E.; Schurmann, P.; Bartosch, B.; Cosset, F.L.; Patel, A.H.; Meisel, H.; Baumert, J.; Viazov, S.; et al. Rapid induction of virus-neutralizing antibodies and viral clearance in a single-source outbreak of hepatitis C. Proc. Natl. Acad. Sci. USA 2007, 104, 6025-6030. [CrossRef] [PubMed]

13. Raghuraman, S.; Park, H.; Osburn, W.O.; Winkelstein, E.; Edlin, B.R.; Rehermann, B. Spontaneous clearance of chronic hepatitis $C$ virus infection is associated with appearance of neutralizing antibodies and reversal of T-cell exhaustion. J. Infect. Dis. 2012, 205, 763-771. [CrossRef] [PubMed]

14. Bukh, J.; Engle, R.E.; Faulk, K.; Wang, R.Y.; Farci, P.; Alter, H.J.; Purcell, R.H. Immunoglobulin with high-titer in vitro cross-neutralizing hepatitis $C$ virus antibodies passively protects chimpanzees from homologous, but not heterologous, challenge. J. Virol. 2015, 89, 9128-9132. [CrossRef] [PubMed]

15. Morin, T.J.; Broering, T.J.; Leav, B.A.; Blair, B.M.; Rowley, K.J.; Boucher, E.N.; Wang, Y.; Cheslock, P.S.; Knauber, M.; Olsen, D.B.; et al. Human monoclonal antibody HCV1 effectively prevents and treats HCV infection in chimpanzees. PLoS Pathog. 2012, 8, e1002895. [CrossRef] [PubMed]

16. Rossi, C.; Butt, Z.; Wong, S.; Buxton, J.; Islam, N.; Yu, A.; Darvishian, M.; Gilbert, M.; Wong, J.; Chapinal, N.; et al. Hepatitis $C$ virus reinfection after successful treatment with direct-acting antiviral therapy in a large population-based cohort. J. Hepatol. 2018, 69, 1007-1014. [CrossRef] [PubMed]

17. Smith, D.B.; Bukh, J.; Kuiken, C.; Muerhoff, A.S.; Rice, C.M.; Stapleton, J.T.; Simmonds, P. Expanded classification of hepatitis $C$ virus into 7 genotypes and 67 subtypes: Updated criteria and genotype assignment web resource. Hepatology 2014, 59, 318-327. [CrossRef] [PubMed]

18. Davis, G.L. Hepatitis C virus genotypes and quasispecies. Am. J. Med. 1999, 107, 21S-26S. [CrossRef] 
19. Farci, P.; Alter, H.J.; Govindarajan, S.; Wong, D.C.; Engle, R.; Lesniewski, R.R.; Mushahwar, I.K.; Desai, S.M.; Miller, R.H.; Ogata, N.; et al. Lack of protective immunity against reinfection with hepatitis $C$ virus. Science 1992, 258, 135-140. [CrossRef] [PubMed]

20. Fuerst, T.R.; Pierce, B.G.; Keck, Z.Y.; Foung, S.K.H. Designing a B cell-based vaccine against a highly variable hepatitis C virus. Front. Microbiol. 2017, 8, 2692. [CrossRef] [PubMed]

21. Kinchen, V.J.; Cox, A.L.; Bailey, J.R. Can broadly neutralizing monoclonal antibodies lead to a hepatitis C virus vaccine? Trends Microbiol. 2018, 26, 854-864. [CrossRef] [PubMed]

22. Law, M.; Maruyama, T.; Lewis, J.; Giang, E.; Tarr, A.W.; Stamataki, Z.; Gastaminza, P.; Chisari, F.V.; Jones, I.M.; Fox, R.I.; et al. Broadly neutralizing antibodies protect against hepatitis $C$ virus quasispecies challenge. Nat. Med. 2008, 14, 25-27. [CrossRef] [PubMed]

23. Schiano, T.D.; Charlton, M.; Younossi, Z.; Galun, E.; Pruett, T.; Tur-Kaspa, R.; Eren, R.; Dagan, S.; Graham, N.; Williams, P.V.; et al. Monoclonal antibody HCV-ABXTL68 in patients undergoing liver transplantation for HCV: Results of a phase 2 randomized study. Liver Transpl. 2006, 12, 1381-1389. [CrossRef] [PubMed]

24. Ray, R.; Meyer, K.; Banerjee, A.; Basu, A.; Coates, S.; Abrignani, S.; Houghton, M.; Frey, S.E.; Belshe, R.B. Characterization of antibodies induced by vaccination with hepatitis $\mathrm{C}$ virus envelope glycoproteins. J. Infect. Dis. 2010, 202, 862-866. [CrossRef] [PubMed]

25. Wang, X.; Yan, Y.; Gan, T.; Yang, X.; Li, D.; Zhou, D.; Sun, Q.; Huang, Z.; Zhong, J. A trivalent HCV vaccine elicits broad and synergistic polyclonal antibody response in mice and rhesus monkey. Gut 2017. [CrossRef] [PubMed]

26. Garrone, P.; Fluckiger, A.C.; Mangeot, P.E.; Gauthier, E.; Dupeyrot-Lacas, P.; Mancip, J.; Cangialosi, A.; Du Chene, I.; LeGrand, R.; Mangeot, I.; et al. A prime-boost strategy using virus-like particles pseudotyped for HCV proteins triggers broadly neutralizing antibodies in macaques. Sci. Transl. Med. 2011, 3, 94 ra71. [CrossRef] [PubMed]

27. Liao, H.X.; Lynch, R.; Zhou, T.; Gao, F.; Alam, S.M.; Boyd, S.D.; Fire, A.Z.; Roskin, K.M.; Schramm, C.A.; Zhang, Z.; et al. Co-evolution of a broadly neutralizing HIV-1 antibody and founder virus. Nature 2013, 496, 469-476. [CrossRef] [PubMed]

28. Rusert, P.; Kouyos, R.D.; Kadelka, C.; Ebner, H.; Schanz, M.; Huber, M.; Braun, D.L.; Hoze, N.; Scherrer, A.; Magnus, C.; et al. Determinants of HIV-1 broadly neutralizing antibody induction. Nat. Med. 2016, 22, 1260-1267. [CrossRef] [PubMed]

29. Sather, D.N.; Carbonetti, S.; Malherbe, D.C.; Pissani, F.; Stuart, A.B.; Hessell, A.J.; Gray, M.D.; Mikell, I.; Kalams, S.A.; Haigwood, N.L.; et al. Emergence of broadly neutralizing antibodies and viral coevolution in two subjects during the early stages of infection with human immunodeficiency virus type 1. J. Virol. 2014, 88, 12968-12981. [CrossRef] [PubMed]

30. Logvinoff, C.; Major, M.E.; Oldach, D.; Heyward, S.; Talal, A.; Balfe, P.; Feinstone, S.M.; Alter, H.; Rice, C.M.; McKeating, J.A. Neutralizing antibody response during acute and chronic hepatitis $\mathrm{C}$ virus infection. Proc. Natl. Acad. Sci. USA 2004, 101, 10149-10154. [CrossRef] [PubMed]

31. Binley, J.M.; Lybarger, E.A.; Crooks, E.T.; Seaman, M.S.; Gray, E.; Davis, K.L.; Decker, J.M.; Wycuff, D.; Harris, L.; Hawkins, N.; et al. Profiling the specificity of neutralizing antibodies in a large panel of plasmas from patients chronically infected with human immunodeficiency virus type 1 subtypes B and C. J. Virol. 2008, 82, 11651-11668. [CrossRef] [PubMed]

32. Doria-Rose, N.A.; Klein, R.M.; Daniels, M.G.; O’Dell, S.; Nason, M.; Lapedes, A.; Bhattacharya, T.; Migueles, S.A.; Wyatt, R.T.; Korber, B.T.; et al. Breadth of human immunodeficiency virus-specific neutralizing activity in sera: Clustering analysis and association with clinical variables. J. Virol. 2010, 84, 1631-1636. [CrossRef] [PubMed]

33. Bretana, N.A.; Boelen, L.; Bull, R.; Teutsch, S.; White, P.A.; Lloyd, A.R.; Luciani, F.; HITS-p Investigators. Transmission of hepatitis C virus among prisoners, Australia, 2005-2012. Emerg. Infect. Dis. 2015, 21, 765-774. [CrossRef] [PubMed]

34. Dolan, K.; Teutsch, S.; Scheuer, N.; Levy, M.; Rawlinson, W.; Kaldor, J.; Lloyd, A.; Haber, P. Incidence and risk for acute hepatitis C infection during imprisonment in Australia. Eur. J. Epidemiol. 2010, 25, 143-148. [CrossRef] [PubMed]

35. Luciani, F.; Bretana, N.A.; Teutsch, S.; Amin, J.; Topp, L.; Dore, G.J.; Maher, L.; Dolan, K.; Lloyd, A.R.; HITS-p Investigators. A prospective study of hepatitis C incidence in Australian prisoners. Addiction 2014, 109, 1695-1706. [CrossRef] [PubMed] 
36. Pham, S.T.; Bull, R.A.; Bennett, J.M.; Rawlinson, W.D.; Dore, G.J.; Lloyd, A.R.; White, P.A. Frequent multiple hepatitis $C$ virus infections among injection drug users in a prison setting. Hepatology 2010, 52, 1564-1572. [CrossRef] [PubMed]

37. Walker, M.R.; Li, H.; Teutsch, S.; Betz-Stablein, B.; Luciani, F.; Lloyd, A.R.; Bull, R.A. Incident hepatitis C virus genotype distribution and multiple infection in australian prisons. J. Clin. Microbiol. 2016, 54, 1855-1861. [CrossRef] [PubMed]

38. White, B.; Madden, A.; Hellard, M.; Kerr, T.; Prins, M.; Page, K.; Dore, G.J.; Maher, L. Increased hepatitis $C$ virus vaccine clinical trial literacy following a brief intervention among people who inject drugs. Drug Alcohol Rev. 2013, 32, 419-425. [CrossRef] [PubMed]

39. White, B.; Madden, A.; Prins, M.; Hellard, M.; Wand, H.; Dore, G.J.; Page, K.; Maher, L. Assessing the feasibility of hepatitis $C$ virus vaccine trials: Results from the hepatitis $C$ incidence and transmission study-community (hits-C) vaccine preparedness study. Vaccine 2014, 32, 5460-5467. [CrossRef] [PubMed]

40. White, B.; Dore, G.J.; Lloyd, A.R.; Rawlinson, W.D.; Maher, L. Opioid substitution therapy protects against hepatitis C virus acquisition in people who inject drugs: The hits-C study. Med. J. Aust. 2014, 201, 326-329. [CrossRef] [PubMed]

41. Cunningham, E.B.; Hajarizadeh, B.; Bretana, N.A.; Amin, J.; Betz-Stablein, B.; Dore, G.J.; Luciani, F.; Teutsch, S.; Dolan, K.; Lloyd, A.R.; et al. Ongoing incident hepatitis C virus infection among people with a history of injecting drug use in an Australian prison setting, 2005-2014: The hits-p study. J. Viral Hepat. 2017, 24, 733-741. [CrossRef] [PubMed]

42. Keck, Z.Y.; Li, S.H.; Xia, J.; von Hahn, T.; Balfe, P.; McKeating, J.A.; Witteveldt, J.; Patel, A.H.; Alter, H.; Rice, C.M.; et al. Mutations in hepatitis C virus E2 located outside the CD81 binding sites lead to escape from broadly neutralizing antibodies but compromise virus infectivity. J. Virol. 2009, 83, 6149-6160. [CrossRef] [PubMed]

43. Tarr, A.W.; Owsianka, A.M.; Szwejk, A.; Ball, J.K.; Patel, A.H. Cloning, expression, and functional analysis of patient-derived hepatitis C virus glycoproteins. Methods Mol. Biol. 2007, 379, 177-197. [PubMed]

44. Urbanowicz, R.A.; McClure, C.P.; King, B.; Mason, C.P.; Ball, J.K.; Tarr, A.W. Novel functional hepatitis C virus glycoprotein isolates identified using an optimized viral pseudotype entry assay. J. Gen. Virol. 2016, 97, 2265-2279. [CrossRef] [PubMed]

45. Bartosch, B.; Dubuisson, J.; Cosset, F.L. Infectious hepatitis C virus pseudo-particles containing functional E1-E2 envelope protein complexes. J. Exp. Med. 2003, 197, 633-642. [CrossRef] [PubMed]

46. Dowd, K.A.; Hershow, R.C.; Yawetz, S.; Larussa, P.; Diaz, C.; Landesman, S.H.; Paul, M.E.; Read, J.S.; Lu, M.; Thomas, D.L.; et al. Maternal neutralizing antibody and transmission of hepatitis C virus to infants. J. Infect. Dis. 2008, 198, 1651-1655. [CrossRef] [PubMed]

47. Bull, R.A.; Leung, P.; Gaudieri, S.; Deshpande, P.; Cameron, B.; Walker, M.; Chopra, A.; Lloyd, A.R.; Luciani, F. Transmitted/founder viruses rapidly escape from $\mathrm{CD} 8^{+} \mathrm{T}$ cell responses in acute hepatitis $\mathrm{C}$ virus infection. J. Virol. 2015, 89, 5478-5490. [CrossRef] [PubMed]

48. Lu, S. Heterologous prime-boost vaccination. Curr. Opin. Immunol. 2009, 21, 346-351. [CrossRef] [PubMed]

49. Janeway, C.A.; Travers, P.; Walport, M.; Shlomchik, M.J. Immunobiology: The Immune System in Health and Disease; Garland Science Publishing: Abingdon, Oxford, UK, 2005.

50. Nachbagauer, R.; Choi, A.; Hirsh, A.; Margine, I.; Iida, S.; Barrera, A.; Ferres, M.; Albrecht, R.A.; Garcia-Sastre, A.; Bouvier, N.M.; et al. Defining the antibody cross-reactome directed against the influenza virus surface glycoproteins. Nat. Immunol. 2017, 18, 464-473. [CrossRef] [PubMed]

51. Law, J.L.; Chen, C.; Wong, J.; Hockman, D.; Santer, D.M.; Frey, S.E.; Belshe, R.B.; Wakita, T.; Bukh, J.; Jones, C.T.; et al. A hepatitis $\mathrm{C}$ virus (HCV) vaccine comprising envelope glycoproteins GPE1/GPE2 derived from a single isolate elicits broad cross-genotype neutralizing antibodies in humans. PLoS ONE 2013, 8, e59776. [CrossRef] [PubMed]

52. Rodrigo, C.; Leung, P.; Lloyd, A.R.; Bull, R.A.; Luciani, F.; Grebely, J.; Dore, G.J.; Applegate, T.; Page, K.; Bruneau, J.; et al. Genetic variability of within-host hepatitis C variants in acute infection. J. Viral Hepat.. accepted for publication 2018.

53. Bailey, J.R.; Flyak, A.I.; Cohen, V.J.; Li, H.; Wasilewski, L.N.; Snider, A.E.; Wang, S.; Learn, G.H.; Kose, N.; Loerinc, L.; et al. Broadly neutralizing antibodies with few somatic mutations and hepatitis $\mathrm{C}$ virus clearance. JCI Insight 2017, 2. [CrossRef] [PubMed] 
54. Mikell, I.; Sather, D.N.; Kalams, S.A.; Altfeld, M.; Alter, G.; Stamatatos, L. Characteristics of the earliest cross-neutralizing antibody response to HIV-1. PLoS Pathog. 2011, 7, e1001251. [CrossRef]

55. McLinden, R.; Paris, R.; Polonis, V.; Close, N.; Su, Z.; Shikuma, C.; Margolis, D.; Kim, J. Association of HIV neutralizing antibody with lower viral load after treatment interruption in a prospective trial (a5170). AIDS 2012, 26, 1452. [CrossRef] [PubMed]

56. Piantadosi, A.; Panteleeff, D.; Blish, C.A.; Baeten, J.M.; Jaoko, W.; McClelland, R.S.; Overbaugh, J. Breadth of neutralizing antibody response to human immunodeficiency virus type 1 is affected by factors early in infection but does not influence disease progression. J. Virol. 2009, 83, 10269-10274. [CrossRef] [PubMed]

57. Swann, R.E.; Cowton, V.M.; Robinson, M.W.; Cole, S.J.; Barclay, S.T.; Mills, P.R.; Thomson, E.C.; McLauchlan, J.; Patel, A.H. Broad anti-hepatitis C virus (HCV) antibody responses are associated with improved clinical disease parameters in chronic hcv infection. J. Virol. 2016, 90, 4530-4543. [CrossRef] [PubMed]

(C) 2018 by the authors. Licensee MDPI, Basel, Switzerland. This article is an open access article distributed under the terms and conditions of the Creative Commons Attribution (CC BY) license (http://creativecommons.org/licenses/by/4.0/). 